DOI: $\underline{\text { https://doi.org/10.24867/04BE22Zepinic }}$

\title{
VIŠEKRITERIJUMSKO ODLUČIVANJE U PLANIRANJU RAZVOJA DISTRIBUTIVNIH MREŽA
}

\section{MULTIPLE ATTRIBUTE DECISION MAKING IN DEVELOPMENT PLANNING OF DISTRIBUTION NETWORKS}

\author{
Tamara Žepinić, Fakultet tehničkih nauka, Novi Sad
}

\begin{abstract}
Oblast - ELEKTROTEHNIKA I RAČUNARSTVO
Kratak sadržaj - U radu su implementirane metode za višsekriterijumsko odlučivanje VIKOR $i$ TOPSIS na primeru ekonomske analize u planiranju razvoja distributivne mreže. Nakon implementacije, napravljeno je poređenje metoda na osnovu analize dobijenih rezultata i njihovih matematičkih osnova.
\end{abstract}

Ključne reči: Planiranje razvoja distributivnih mreža, višekriterijumska optimizacija i odlučivanje

\begin{abstract}
In this paper, the methods for multiple attribute decision making VIKOR and TOPSIS are implemented in the case of economic analysis in the development planning of distribution network. After implementation, a comparison was made between the methods based on the analysis of the obtained results and their mathematical bases.
\end{abstract}

Keywords: Development planning of electricity distribution networks, multiple attribute decision making

\section{UVOD}

Ciljevi planiranja razvoja distributivne mreže uključuju minimizaciju gubitaka energije i potrebnih investicija (troškova ulaganja), povećanje pouzdanosti i lične sigurnosti i dobar kvalitet električne energije, kao i očuvanje životne sredine [1]. U ovom radu je razmatrano planiranje razvoja distributivne mreže sa ciljem povećanja pouzdanosti uz minimizaciju potrebnih investicija. Pouzdanost odnosno neprekidnost napajanja sa stanovišta korisnika najčešće predstavlja najznačajniji tehnički aspekt kvaliteta električne energije.

Pouzdanost se najčešće meri učestanošću i dužinom trajanja prekida napajanja korisnika, odnosno indeksima (pokazateljima) pouzdanosti SAIFI i SAIDI. Uobičajene strategije korišćene za unapređenje pouzdanosti su smanjenje broja kvarova u mreži, smanjenje dužine trajanja prekida $\mathrm{u}$ napajanju i smanjenje broja korisnika pogođenih kvarovima. Indeksi pouzdanosti SAIDI i SAIFI uvek su bili među najvažnijim pokazateljima koji su se koristili kod planiranja izgradnje i unapređenja distributivne mreže. Postoji više različitih strategija za unapređenje ovih pokazatelja pouzdanosti [2]. Jedna od strategija za njihovo unapređenje je i smanjenje broja kvarova kroz smanjenje intenziteta otkaza elemenata ditributivnih

\footnotetext{
NAPOMENA:

Ovaj rad proistekao je iz master rada čiji mentor je bio doc. dr Željko Popović.
}

mreža. Ova strategija je i razmatrana u ovom radu. Ona je zasnovana na zameni postojećih sekcija mreže sa novim sekcijama koje imaju manji intenzitet otkaza $(\lambda)$. U cilju određivanja najboljeg rešenja, odnosno skupa postojećih sekcija koje treba zameniti novim tako da se minimiziraju SAIDI, SAIFI i investicioni troškovi, potrebno je definisati skup većeg broja različitih alternativa zamene postojećih sekcija. Zatim, na osnovu navedenog kriterijuma treba izabrati najbolju varijantu iz skupa generisanih alternativa. Sve alternative zamene postojećih sekcija će biti poređene po nekoliko kriterijuma i to vrednost investicije [n.j.], vrednost indeksa pouzdanosti SAIDI $\left[\frac{\mathrm{h}}{\mathrm{god}}\right]$ i vrednost indeksa pouzdanosti SAIFI $\left[\frac{\mathrm{kvar}}{\mathrm{god}}\right]$. Pošto su svi kriterijumi izraženi u različitim jedinicama, potrebno je koristiti optimizaciju po više kriterijuma, odnosno višekriterijumsku optimizaciju. Da bi se rešio zadatak izbora najboljeg rešenja iz skupa alternativa, razvijene su metode za višekriterijumsku optimizaciju. U nastavku će detaljnije biti objašnjene metode VIKOR i TOPSIS koje se koriste za određivanje višekriterijumski optimalnog rešenja i koje će biti implementirane na primeru višekriterijumskog odlučivanja u radu.

\section{VIŠEKRITERIJUMSKO ODLUČIVANJE I KOMPROMISNO REŠENJE}

Zadatak višekriterijumskog odlučivanja može se formulisati na sledeći način [3]:

$$
v k o_{a \in A}\left(f_{1}(a), f_{2}(a), \ldots, f_{n}(a)\right) \text {, }
$$

gde je : $A$ - skup dopustivih (potencijalnih) alternativa, $a=\left(x_{1}, x_{2}, \ldots\right)$ - alternativa dobijena za određene vrednosti promenljivih $(x)$ sistema, $f_{i}$ - $i$-ta kriterijumska funkcija, vko - operator za višekriterijumsko optimalno rešenje.

Metode za višekriterijumsku optimizaciju koje se koriste za rešavanje zadataka izbora najboljeg rešenja iz datog (konačnog) skupa alternativa $\left\{a_{1}, a_{2}, \ldots, a_{J}\right\}$ često imaju i zadatak da odrede redosled (rang-listu) sa stanovišta svih datih kriterijuma. Ako postoji rešenje koje istovremeno maksimizira/minimizira sve kriterijumske funkcije, onda je ono optimalno rešenje postavljenog zadatka. Međutim, takvo rešenje retko postoji u realnim (praktičnim) problemima višekriterijumske optimizacije, pa se mora usvojiti jedno rešenje kao najbolje.

Metode za višekriterijumsku optimizaciju VIKOR i TOPSIS su nastale kao verzije metode kompromisnog programiranja kojom se određuje skup kompromisnih rešenja. Kompromisno rešenje je najbliže idealnom prema 
datoj meri rastojanja. Obe metode zahtevaju da svaka alternativa bude vrednovana po svim kriterijumima, pa se vrednost $i$-te kriterijumske funkcije za alternativu $a_{j}$ može označiti sa $f_{i j}$. Neophodno je da se traži maksimum ako $i$-ta kriterijumska funkcija predstavlja korist ili dobit, ili minimum za štete ili troškove.

Takođe, obe metode koriste normalizovane vrednosti težina kriterijumskih funkcija $w_{i}, i=1, \ldots, n$ koje su neophodne jer se ne može pretpostaviti da sve kriterijumske funkcije imaju jednaku važnost, pri čemu mora važiti da je $\sum w_{i}=1, w_{i} \geq 0, \forall i$. Težina uz $i$-tu kriterijumsku funkciju može imati veću ili manju vrednost $\mathrm{u}$ odnosu na zadatu početnu vrednost $w_{i}$, ali promenom jedne težine $\left(w_{i}\right)$ moraju se promeniti i ostale težine tako da i dalje važi da je $\sum w_{i}=1, w_{i} \geq 0, \forall i$. Konačnu odluku o tome koja alternativa će biti izabrana donosi donosilac odluke (nadležno i odgovorno lice za donošenje konačne odluke, odnosno za usvajanje konačnog, optimalnog rešenja) [3].

\subsection{Metoda VIKOR}

Metoda VIKOR za Višekriterijumsko Kompromisno Rangiranje ili (Višekriterijumsko Kompromisno Rešenje) [3] zahteva da su poznate vrednosti svih kriterijumskih funkcija za sve alternative, u vidu matrice $\left|f_{i j}\right|_{n \times j}$. Metoda VIKOR određuje kompromisno rešenje koje može biti jedna alternativa ili skup alternativa, za date (ulazne) vrednosti težina kriterijuma $w_{i}, i=1, \ldots, n$. Za određivanje kompromisne rang-liste treba najpre odrediti meru $S_{j}$ kojom se određuje "najbolja" alternativa koja zadovoljava "većinu" (sumu) kriterijuma, kao i meru $R_{j}$ kojom se određuje alternativa koja nije "izrazito loša" prema nekom kriterijumu. Pomenute mere se određuju za sve analizirane alternative $a_{j}, j=1, \ldots, J$ pomoću sledećih relacija:

$$
\begin{gathered}
S_{j}=\sum_{i=1}^{n} w_{i}\left(f_{i}^{*}-f_{i j}\right) /\left(f_{i}^{*}-f_{i}^{-}\right), \\
R_{j}=\max _{i}\left[w_{i}\left(f_{i}^{*}-f_{i j}\right) /\left(f_{i}^{*}-f_{i}^{-}\right)\right],
\end{gathered}
$$

gde je: $\mathrm{n}$ - broj kriterijuma, $w_{i}$ - težina $i$-te kriterijumske funkcije, $f_{i j}$ - vrednost $i$-te kriterijumske funkcije za $j$-tu alternativu, $f_{i}^{*}$ - najbolja alternativa svakog $i$-tog kriterijuma, $f_{i}^{-}$najlošija alternativa svakog $i$-tog kriterijuma. Rangiranje se vrši sortiranjem alternativa prema vrednostima mere $Q_{j}$ koja predstavlja linearnu funkciju težine strategije "zadovoljavanja većine kriterijuma" i određuje se pomoću sledeće relacije:

$$
Q_{j}=v \frac{\left(S_{j}-S^{*}\right)}{\left(S^{-}-S^{*}\right)}+(1-v) \frac{\left(R_{j}-R^{*}\right)}{\left(R^{-}-R^{*}\right)},
$$

gde je: $v$ - vrednost težine koja zavisi od broja kriterijuma (n) i u primeru koji sledi usvojeno je da je $v=0.5$ za $n \leq 4, S^{*}=\min _{j} S_{j}, S^{-}=\max _{j} S_{j}, R^{*}=\min _{j} R_{j}$ i $R^{-}=\max _{j} R_{j}$. Najbolja alternativa je ona za koju je vrednost mere najmanja i ona zauzima prvo mesto na rang-listi. Metoda VIKOR predlaže kao višekriterijumski najbolju alternativu (za date težine $w_{i}$ ) onu koja je na prvoj poziciji na kompromisnoj rang-listi samo ukoliko ima "dovoljnu prednost" nad alternativom sa sledeće pozicije. Za vrednovanje "prednosti" koristi se razlika između mera $Q_{j}$. Alternativa $a^{\prime}$ ima dovoljnu prednost nad sledećom $a^{\prime \prime}$ sa rang-liste ako je:

$$
Q\left(a^{\prime \prime}\right)-Q\left(a^{\prime}\right) \geq D Q
$$

gde je $D Q$ “prag prednosti” koji se određuje kao:

$$
D Q=\min (0.25 ; 1 /(J-1)),
$$

gde je $J$ ukupan broj analiziranih alternativa.

Sa 0.25 je ograničen prag za slučajeve sa malim brojem alternativa. Uslov "dovoljne prednosti" omogućava da se donosiocu odluke prikažu sve alternative koje su "bliske" u višekriterijumskom smislu. Ne bi bilo opravdano da se donosiocu odluke prikaže samo alternativa sa prve pozicije na rang-listi prema meri $Q_{j}$ i da se zanemare alternative koje imaju njoj "bliske" vrednosti mere $Q_{j}$. Ukoliko prva alternativa sa kompromisne rang-liste ne ispunjava taj uslov tada skup kompromisnih rešenja sadrži alternative sa kompromisne rang-liste $a^{\prime}$ i $a^{\prime \prime}, \ldots, a^{(K)}$ za koje je $Q\left(a^{(K)}\right)-Q\left(a^{\prime}\right)<D Q$, kao što će biti pokazano u razmatranom primeru u radu [3].

\subsection{Metoda TOPSIS}

Metoda TOPSIS (Technique for Order Preference by Similiarity to Ideal Solution) [4] je još jedna verzija proširenja kompromisnog programiranja. Ova metoda je zasnovana na konceptu da izabrana alternativa treba da ima najkraću Euklidovu udaljenost od "idealnog" rešenja i najdalju Euklidovu udaljenost od "anti-idealnog" rešenja, pa se na taj način uvode dve referentne tačke: "idealno rešenje" i "anti-idealno rešenje". Metoda TOPSIS zahteva da su poznate vrednosti svih kriterijumskih funkcija $f_{i}$ iz $F$ vektorske kriterijumske funkcije, $F=\left(f_{1}, f_{2}, \ldots, f_{n}\right)$ u vidu matrice $\left|f_{i j}\right|_{n \times J}$ za sve alternative iz skupa dopustivih (potencijalnih) alternativa $A=\left\{a_{1}, a_{2}, \ldots, a_{J}\right\}$. Metoda TOPSIS na kraju svog algoritma uvek pruža jedinstveno kompromisno rešenje tako što se formiranjem rang-liste svih alternativa na osnovu vrednosti mere $C_{j}^{*}$ bira najbolja alternativa sa najvećom vrednošću $C_{j}^{*}$. Mera $C_{j}^{*}$ proračunava relativnu blizinu "idealnom rešenju" svake alternative $a_{j}, j=$ $1, \ldots, J$ i računa se kao:

$$
C_{j}^{*}=S_{j}^{-} /\left(S_{j}^{*}+S_{j}^{-}\right),
$$

gde je: $S_{j}^{*}$ - Euklidova udaljenost od "idealnog rešenja", $S_{j}^{-}$- Euklidova udaljenost od "anti-idealnog rešenja". $S_{j}^{*}$ se računa kao:

$$
S_{j}^{*}=\sqrt{\sum_{i=1}^{n}\left[w_{i} \frac{f_{i j}}{\sqrt{\sum_{j=1}^{J} f_{i j}^{2}}}-v_{i}^{*}\right]^{2}}
$$

gde je : n - broj kriterijuma, $w_{i}$ - težina $i$-te kriterijumske funkcije, $f_{i j}$ - vrednost $i$-te kriterijumske funkcije za $j$-tu alternativu, $\quad v_{i}^{*}=\max _{j}\left[w_{i} \frac{f_{i j}}{\sqrt{\sum_{j=1}^{J} f_{i j}^{2}}}\right]$ ako kriterijumska funkcija predstavlja korist ili $v_{i}^{*}=\min _{j}\left[w_{i} \frac{f_{i j}}{\sqrt{\sum_{j=1}^{J} f_{i j}^{2}}}\right]$ ako kriterijumska funkcija predstavlja štetu. $S_{j}^{-}$se računa kao:

$$
S_{j}^{-}=\sqrt{\sum_{i=1}^{n}\left[w_{i} \frac{f_{i j}}{\sqrt{\sum_{j=1}^{J} f_{i j}^{2}}}-v_{i}^{-}\right]^{2}},
$$


gde je $: v_{i}^{*}=\min _{j}\left[w_{i} \frac{f_{i j}}{\sqrt{\sum_{j=1}^{J} f_{i j}^{2}}}\right]$ ako kriterijumska funkcija predstavlja korist ili $v_{i}^{*}=\max _{j}\left[w_{i} \frac{f_{i j}}{\sqrt{\sum_{j=1}^{J} f_{i j}^{2}}}\right] \quad$ ako kriterijumska funkcija predstavlja štetu.

\section{PRIMENA METODA VIKOR I TOPSIS}

U ovom delu rada je prikazana primena metoda VIKOR i TOPSIS na primeru ekonomske analize u planiranju razvoja distributivnih mreža. U razmatranom primeru je primenjena uobičajena strategija za unapređenje pouzdanosti napajanja $\mathrm{i}$ to smanjenje broja kvarova $\mathrm{u}$ mreži zamenom postojećih sekcija mreže sa novim sekcijama koje imaju manji intenzitet otkaza $(\lambda)$. Problem višekriterijumske optimizacije se u ovome radu rešava korišćenjem heurističkog pristupa. Ovaj pristup definiše skup heurističkih pravila za određivanje skupa sekcija mreže koje bi bile zamenjene novim sekcijama koje imaju manji intenzitet otkaza $(\lambda)$. Heuristička pravila koja će biti primenjena u nastavku su:

1. Zamena svih sekcija mreže;

2. Zamena svih sekcija najkritičnijeg/ih izvoda. Pod najkritičnijim izvodima se smatraju svi izvodi koji sadrže najveći broj sekcija čiji je intenzitet otkaza $\lambda \geq \lambda_{\text {prosečno }}$, gde je $\lambda_{\text {prosečno }}$ prosečni intenzitet otkaza svih sekcija mreže;

3. Zamena najkritičnijih sekcija jednog ili više izvoda. Pod najkritičnijim sekcijama se smatraju sve sekcije čiji je intenzitet otkaza $\lambda \geq \lambda_{\text {prosečno }}$, gde je

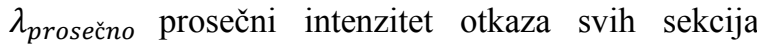
mreže;

4. Zamena svih najkritičnijih sekcija mreže. Pod najkritičnijim sekcijama se smatraju sve sekcije čiji je intenzitet otkaza $\lambda=\lambda_{\text {najgore }}$, gde je $\lambda_{\text {najgore }}$ najveći zabeleženi intenzitet otkaza sekcije $\lambda$ u mreži;

5. Zamena sekcije svakog izvoda koja je najbliža izvoru napajanja, pod uslovom da je intenzitet otkaza te sekcije $\lambda \geq \frac{\lambda_{\text {najgore }}}{2}$, gde je $\lambda_{\text {najgore }}$ najveći zabeleženi intenzitet otkaza sekcije $\lambda$ u mreži;

6. Zamena sekcije svakog izvoda koja je najdalja od izvora napajanja, pod uslovom da je intenzitet otkaza te sekcije $\lambda \geq \frac{\lambda_{\text {najgore }}}{2}$, gde je $\lambda_{\text {najgore najveći }}$ zabeleženi intenzitet otkaza sekcije $\lambda$ u mreži;

7. Zamena svih sekcija čija je dužina $l \geq l_{\text {prosečno }}$ i čiji je intenzitet otkaza $\lambda \geq \lambda_{\text {prosečno }}$, gde je $l_{\text {prosečno }}$ prosečna dužina svih sekcija mreže, a $\lambda_{\text {prosečno }}$ prosečni intenzitet otkaza svih sekcija mreže.

Po uzoru na ova heuristička pravila na primeru test mreže sa slike 1 definisano je 10 različitih alternativa zamene postojećih sekcija, te je potrebno izabrati najbolju tako što će se sve alternative porediti po nekoliko kriterijuma. Zamena starih sekcija novim sekcijama je simulirana promenom intenziteta otkaza sa stare vrednosti na 0.1 $\frac{\text { kvar }}{\text { god }}$. U mreži postoji šest izvoda sa različitim dužinama sekcija, tako da su ukupne dužine izvoda u opsegu $2.5-7$ $\mathrm{km}$, dok su intenziteti otkaza sekcija u opsegu $0.01-0.06$ $\frac{\text { kvar }}{\text { god }}$. Broj potrošača na svakom izvodu je između 100 i 700 .

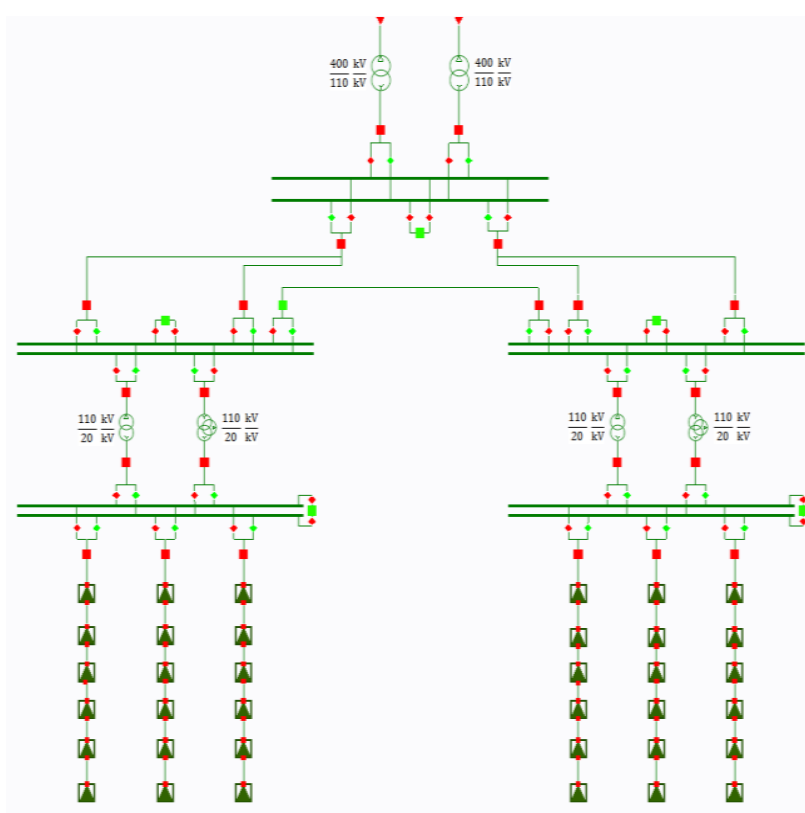

Slika 1. Test mreža

\subsection{Razmatrani kriterijumi}

Sve alternative se vrednuju na osnovu tri kriterijuma, odnosno kriterijumske funkcije:

1. Vrednost investicije [n.j.].

2. Vrednost indeksa pouzdanosti SAIDI $\left[\frac{\mathrm{h}}{\mathrm{god}}\right]$.

3. Vrednost indeksa pouzdanosti SAIFI $\left[\frac{\mathrm{kvar}}{\mathrm{god}}\right]$.

$\mathrm{Na}$ osnovu prethodno definisanih kriterijumskih funkcija, vidi se da njihove vrednosti nisu izražene $u$ istim jedinicama mere, zbog čega je neophodno koristiti metode višekriterijumskog odlučivanja, VIKOR i TOPSIS. Za proračune je potrebno imati vrednosti težina kriterijuma $\mathrm{i}$ $\mathrm{u}$ ovom primeru svim kriterijumima su dodeljene iste težine $u$ vrednosti od 0.33. Finalna VIKOR rang-lista prema meri $Q_{j}$ za prve dve rangirane alternative prikazana je u tabeli 1 .

Tabela 1. Rang-lista VIKOR prema meri $Q_{j}$

\begin{tabular}{|c|c|c|}
\hline $\begin{array}{c}\text { Pozicija na } \\
\text { rang-listi }\end{array}$ & Alternativa & $Q_{j}$ \\
\hline 1. & 5. & 0.060 \\
\hline 2. & 4. & 0.145 \\
\hline
\end{tabular}

$\mathrm{Na}$ osnovu podataka iz tabele 1 može se izračunati "prednost" alternative koja zauzima prvo mesto na kompromisnoj rang-listi nad alternativom koja zauzima drugo mesto. Ta "prednost" iznosi 0.085, pa se može doneti zaključak da prva alternativa ne ispunjava uslov "dovoljne prednosti" nad alternativom sa sledeće pozicije rang-liste jer "prag prednosti" koji iznosi 0.11 nije postignut. Zbog toga se metodom VIKOR dobija skup kompromisnih rešenja u koji ulaze i prva i druga alternativa sa kompromisne rang-liste koje se zajedno predlažu donosiocu odluke. Prva alternativa sa kompromisne rang-liste predstavlja zamenu svih sekcija 
čiji su intenziteti otkaza 0.6 ili $0.5 \frac{\mathrm{kvar}}{\mathrm{god}}$. Ova alternativa je definisana po uzoru na četvrto predloženo heurističko pravilo. Druga alternativa sa kompromisne rang-liste predstavlja zamenu po tri najkritičnije sekcije svakog izvoda. Ova alternativa je definisana po uzoru na treće predloženo heurističko pravilo.

Finalna TOPSIS rang-lista prema meri $C_{j}^{*}$ za prve dve rangirane alternative prikazana je u tabeli 2 .

Tabela 2. Rang-lista TOPSIS prema meri $C_{j}^{*}$

\begin{tabular}{|c|c|c|}
\hline $\begin{array}{c}\text { Pozicija na } \\
\text { rang-listi }\end{array}$ & Alternativa & $C_{j}^{*}$ \\
\hline 1. & 5. & 0.651 \\
\hline 2. & 10. & 0.590 \\
\hline
\end{tabular}

Metodom TOPSIS je alternativa koja zauzima prvo mesto na kompromisnoj rang-listi određena kao jedinstveno kompromisno rešenje $\mathrm{i}$ to je alternativa zamene svih sekcija čiji su intenziteti otkaza 0.6 ili $0.5 \frac{\mathrm{kvar}}{\mathrm{god}}$.

Kao što je napomenuto u 2. glavi, težina uz $i$-tu kriterijumsku funkciju tj. kriterijum može imati veću ili manju vrednost $\mathrm{u}$ odnosu na zadatu početnu vrednost $w_{i}$, ali promenom jedne težine $\left(w_{i}\right)$ moraju se promeniti $\mathrm{i}$ ostale težine tako da važi da je $\sum w_{i}=1, w_{i} \geq 0, \forall i$. U tabeli 3 su prikazane rang-liste koje su dobijene primenom metoda VIKOR i TOPSIS za nove vrednosti težina kriterijuma, tako da je prvom kriterijumu dodeljena težina od 0.2 , a drugom i trećem kriterijumu od 0.4. U rang-listama su prikazane samo pozicije alternativa koje su bile najbolje rangirane u inicijalnom slučaju kada su sve težine kriterijuma bile jednake. Pozicije alternativa na rang-listama koje su se promenile u odnosu na taj slučaj obeležene su podebljanim brojevima.

Tabela 3. Rang-liste VIKOR i TOPSIS za nove vrednosti težina kriterijuma

\begin{tabular}{|c|c|c|}
\hline Alternativa & $\begin{array}{c}\text { Pozicija na } \\
\text { rang-listi } \\
\text { VIKOR }\end{array}$ & $\begin{array}{c}\text { Pozicija na } \\
\text { rang-listi } \\
\text { TOPSIS }\end{array}$ \\
\hline 4. & $\mathbf{3}$ & $\mathbf{3}$ \\
\hline 5. & $\mathbf{5}$ & $\mathbf{2}$ \\
\hline 10. & 9 & $\mathbf{7}$ \\
\hline
\end{tabular}

\subsection{Diskusija dobijenog kompromisnog rešenja}

Analizom dobijenih rezultata, može se uočiti da su obe metode odredile kao kompromisno rešenje petu alternativu, odnosno zamenu svih sekcija čiji su intenziteti otkaza 0.6 ili $0.5 \frac{\mathrm{kvar}}{\mathrm{god}}$. Međutim, metodom VIKOR je određen skup kompromisnih rešenja u koji pored pomenute alternative ulazi i alternativa koja zauzima drugo mesto na kompromisnoj rang-listi. Donosilac odluke treba da izabere, na osnovu njegovih preferencija, jednu od te dve alternative kao konačno rešenje. Za razliku od metode VIKOR, metoda TOPSIS je na kraju svog algoritma pružila jedinstveno kompromisno rešenje. $\mathrm{Na}$ osnovu podataka iz tabele 3 vidi se da se promenom težina kriterijumskih funkcija dobijaju bitno drugačije rang-liste alternativa u odnosu na prvobitne, što ukazuje na to koliko su metode VIKOR i TOPSIS osetljive na promenu vrednosti težina kriterijumskih funkcija.

\section{ZAKLJUČAK}

$\mathrm{Na}$ osnovu izloženih razmatranja, može se zaključiti da primena metode VIKOR predstavlja bolji izbor za višekriterijumsko odlučivanje, jer ova metoda omogućava da se donosiocu odluke prikaže više alternativa koje pripadaju skupu kompromisnih rešenja kada prva alternativa sa rang-liste nije "dovoljno" bolja od ostalih, kao što je to bio slučaj u primeru višekriterijumskog odlučivanja prikazanom u ovom radu. Sa druge strane, metodom TOPSIS se uvek dobija jedinstveno kompromisno rešenje. Alternativa koja je definisana po uzoru na četvrto predloženo heurističko pravilo je određena kao kompromisno rešenje, pa se heurističko pravilo zamene svih najkritičnijih sekcija mreže predlaže kao najbolje pravilo za unapređenje pouzdanosti. Pošto su sve alternative definisane po uzoru na nekoliko predloženih heurističkih pravila, predmet daljeg istraživanja može biti unapređenje tih heurističkih pravila. $\mathrm{Na}$ kraju primera je pokazano da se promenom težina kriterijumskih funkcija dobijaju bitno drugačije rang-liste alternativa primenom metoda VIKOR i TOPSIS, što ukazuje na to koliko su te metode osetljive na promenu vrednosti težina kriterijumskih funkcija. Zbog navedenog je važno uraditi analizu težina i stabilnosti kompromisnog rešenja sa promenom težina. Ispitivanje ostalih metoda za višekriterijumsku optimizaciju je svakako od veoma velike važnosti i predstavlja predmet daljeg istraživanja.

\section{LITERATURA}

[1] Viktoria Neimane: On development planning of electricity distribution networks; Doctoral Dissertation, Royal Institute of Technology, Stockholm, 2001.

[2] Ž. Popović, S. Knežević, B. Brbaklić: Optimalna strategija za unapređenje pouzdanosti u distributivnim mrežama; Zbornik radova sa desetog savetovanja o elektrodistributivnim mrežama CIRED Srbija, Vrnjačka Banja, R-3.01, 26.-30. Septembar 2016.

[3] Serafim Opricović: Višekriterijumska optimizacija sistema u građevinarstvu; Građevinski fakultet Univerziteta u Beogradu, Beograd, 1998.

[4] Ching-Lai Hwang, Kwangsun Yoon: Multiple Attribute Decision Making- Methods and Applications; Springer-Verlag, Berlin, 1981.

[5] Gwo-Hshiung Tzeng, Jih-Jeng Huang: Multiple Attribute Decision Making- Methods and Applications; CRC Press, London, 2011.

\section{Kratka biografija:}

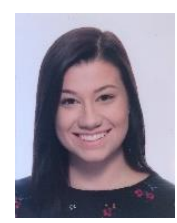

Tamara Žepinić rođena je u Bijeljini 1994. god. Diplomski rad na Fakultetu tehničkih nauka iz oblasti Elektrotehnike i računarstva Elektroenergetski sistemi odbranila je 2017.god. i 2017. god. upisala je master studije na istom fakultetu. 